\title{
PROBLEMS OF BONE MARROW CELL KINETICS
}

\author{
L. G. Lajtha, M.D., D.Phil. \\ Radiobiology Laboratory, Churchill Hospital, Oxford
}

UNTIL about 30 years ago the study of hæmatological problems centred mainly around cellular hæmatology: the morphology of blood and bone marrow cells. The last two decades, however, have witnessed a series of veritable eruptions in the fields of blood coagulation, immune hæmatology, and hæmoglobin structure, not to speak of such factors as folic acid and its derivatives and, of course, vitamin $B_{12}$.

The relative dormancy of cellular hæmatology was mainly due to a lack of suitable new methods for the study of blood and bone marrow cells. A great deal of useful information was, however, obtained with the application of cytochemical methods in hæmatology, but cytochemistry alone still presents a somewhat static picture of cellular metabolism.

The introduction of radioactive iron ${ }^{(59} \mathrm{Fe}$ mainly) and the resulting information-ferrokinetics-only emphasized the need for a better understanding of the underlying cellular functions: which cell type takes up how much iron, how long it takes before the cell matures, how many times it divides, how is a steady state between cell differentiation and cell proliferation maintainedto name only a few of the obvious questions.

The demand for more information at the cellular level has been further increased by the well-known radiosensitivity of the hæmopoietic system and by the possibility of bone marrow grafting in combating radiation damage: 'Finally, and most recently, it has been added to by the discovery of such humoral factors as erythropoietin, asking the obvious questions on their mode of action.

\section{Autoradiography}

The study of bone marrow cells is made difficult by the fact that bone marrow-perhaps more than any other organ in the body-is a markedly heterogeneous population of cells. Erythroid, myeloid, lymphoid, thromboid cells-to name only the main populations-exist side by side; within each line of cells there are several stages of differentiation; there is a complete asynchrony in respect of both differentiation and proliferation.
Consequently, the orthodox biochemicaı ur radiochemical methods, investigating a random sample of this heterogeneous population, only could give information on 'the bone marrow cell', which, of course, is a meaningless fiction.

Autoradiography, however, is a method which, when suitably applied, can give information at the level of individual cells. The method is based on labelling the cells (in vivo or in vitro) with a radioactive material, then preparation of smears and coating these with a very thin layer of fine grain photographic emulsion. The slides are then exposed in the dark. During exposure some of the radioactive disintegrations occurring will emit particles which penetrate the photographic emulsion and thus form a latent image. Subsequent processing of these slides (developing, fixing, staining) will give preparations in which, above the stained cells, the localization and number of photographic grains can be studied. The method and some of the results have been recently reviewed elsewhere (Lajtha, 1957, 196rb).

The main findings with autoradiography may be listed as follows:

(a) The Cell Cycle. With the help of DNA labelling ${ }^{32} \mathrm{P},{ }^{14} \mathrm{C}$ adenine, ${ }^{3} \mathrm{H}$ thymidine, ${ }^{3} \mathrm{H}$ deoxycytidine) the proportion of cells in a population which synthesize DNA, the length of the DNA synthetic period, and consequently the intermitotic cycle time can be measured in individual cell types. The intermitotic time intervals so obtained for human bone marrow cells were: pronormoblasts and basophilic normoblasts, about I 8 to 20 hours; early polychromatic normoblasts, about 30 hours; promyelocytes, about 18 hours; myelocytes, about 30 hours. The middle and late polychromatic normoblasts, and the metamyelocytes and band cells show no evidence of a cell cycle, i.e. they are not dividing cells.

(b) Cytoplasmic Functions. RNA labelling $\left({ }^{3} \mathrm{H}\right.$ uridine, ${ }^{3} \mathrm{H}$ cytidine) indicates a decreasing rate of RNA synthesis as maturation proceeds: highest uptake in pronormoblasts and basophilic normoblasts (and promyelocytes), lower in the early polychromatic normoblasts and myelocytes, very 
low in the late polychromatic normoblasts and metamyelocytes.

Hæmoglobin synthesis can be studied by the uptake of radioactive iron $\left({ }^{59} \mathrm{Fe}\right)$ into erythroblasts and, as with RNA synthesis, ${ }^{59} \mathrm{Fe}$ uptake decreases with increasing maturation. The mean (or better, median) grain-counts indicate the following ratio of decrease: pro- and basophilic normoblasts, I.0; early polychromatic normoblasts, 0.67 ; middle polychromatic normoblasts, 0.5 ; late polychromatic normoblasts, 0.4 ; marrow reticulocytes, about 0.3 or less.

Sodium sulphate $\left({ }^{35} \mathrm{~S}\right)$ uptake-specific for the myeloid series of cells-also shows a decreasing rate with increase in differentiation, as does aminoacid uptake in both the erythroid and myeloid cells.

It appears, therefore-and perhaps not surprisingly-that most metabolic reactions occur faster in the younger cell types than in the more differentiated 'older' cells.

(c) 'Hot' Reticulocytes and Changing Rate of Hamoglobin Synthesis During Cell Cycle. Immediately after injection of a suitable dose of ${ }^{59} \mathrm{Fe}$ the reticulocytes in the peripheral blood show an uptake even lower than the marrow reticulocytes. Based on the rates of uptake in the marrow cells it would be expected that eventually the strongerlabelled marrow reticulocytes and the late normoblasts would somewhat increase the mean graincount of blood reticulocytes. This increase, however, would not be expected to exceed the mean grain-counts of the late normoblasts because the early normoblasts-although they show a higher uptake, i.e. higher grain-counts on autoradiographs-would be expected to divide, and consequently 'dilute' their content of radioactivity, before becoming reticulocytes.

However, 24 hours after administration of ${ }^{59} \mathrm{Fe}$ some reticulocytes will appear in the peripheral blood with quite unexpectedly high grain-counts ('hot' reticulocytes). These cells may exhibit grain-counts as high as the mean grain-count over basophilic normoblasts. As by two hours after injection of ${ }^{59} \mathrm{Fe}$ there is not enough radio-iron in the plasma to effect further labelling, these ' hot' reticulocytes give the impression of some basophilic normoblasts maturing to reticulocytes without intervening division and being released into the blood-all within 24 hours.

It might be thought that it is a 'tall order' to expect a basophilic normoblast to mature without any further cell division into a blood reticulocyte -all within 24 hours. In fact, as will be shown below, the situation is somewhat simpler.

When the rate of the metabolic process is measured in a cell population, it is important to know whether the measured rate is due to a uniform rate in all cells, or is a mean of severai rates occurring in various members of the popuz lation. This information can only be obtained bog autoradiography, by studying the pattern of grainfcount distribution over the cell population i question. The matter is discussed in detail else where (Lajtha, Oliver, Berry and Hell, 1960); is sufficient to say here only that the rate foun in dividing cells (i.e. basophilic and early poly chromatic normoblasts) is a mean rate, and the distribution curves indicate a doubling of the uptake rate of ${ }^{59} \mathrm{Fe}$ in an exponential fashion during the cell cycle. This means that an early polychromatic normoblast will exhibit about twice high an uptake immediately before mitosis immediately after mitosis. In other words? although the mean rate in early polychromatte normoblasts is lower than in basophilic normo blasts, an early polychromatic normoblast immete diately prior to mitosis may show as high or higher uptake than many basophilic normoblasts (i.e. basophilic normoblasts after mitosis, or in the early stages of their cell cycle). Such cells, therefore, if they miss one mitosis, will show up as ' hot' reticulocytes in the peripheral blood.

\section{Kinetic Model of the Erythron}

With the above autoradiographic information - scanty as it may seem to be-adding to it one bit of other information, that of the erythrien differential count of the bone marrow, it possible to construct a kinetic model of the erythron, which indicates cell cycles, intermitoto times, number of mitoses, marrow duration times, rates of hæmoglobin synthesis and hæmoglobi contents at various stages of erythropoiesis.

The construction of the model proceeds follows:

(a) One pronormoblast divides after a 20-hou뵬 cycle.

(b) The resulting daughter cells (at some stage called basophilic normoblasts) also divi@e after a 20-hour cycle. As to the number of cell cycles as basophilic normoblasts, it is determined by the marrow differential couns, i.e. proportion of basophilic normoblasts 畗 the total erythroid population.

(c) When the cells reach the early polychromatic stage, their cell cycle increases to 30 hours

(d) Most of the early polychromatic normoblases divide-but some, those which give rise the 'hot' reticulocytes, do not effect dis sion-and give rise to middle and late pol chromatic normoblasts.

(e) : The latter do not divide: their life span (i.\&. duration of period before loss of the nucleus) is calculated from the bon 


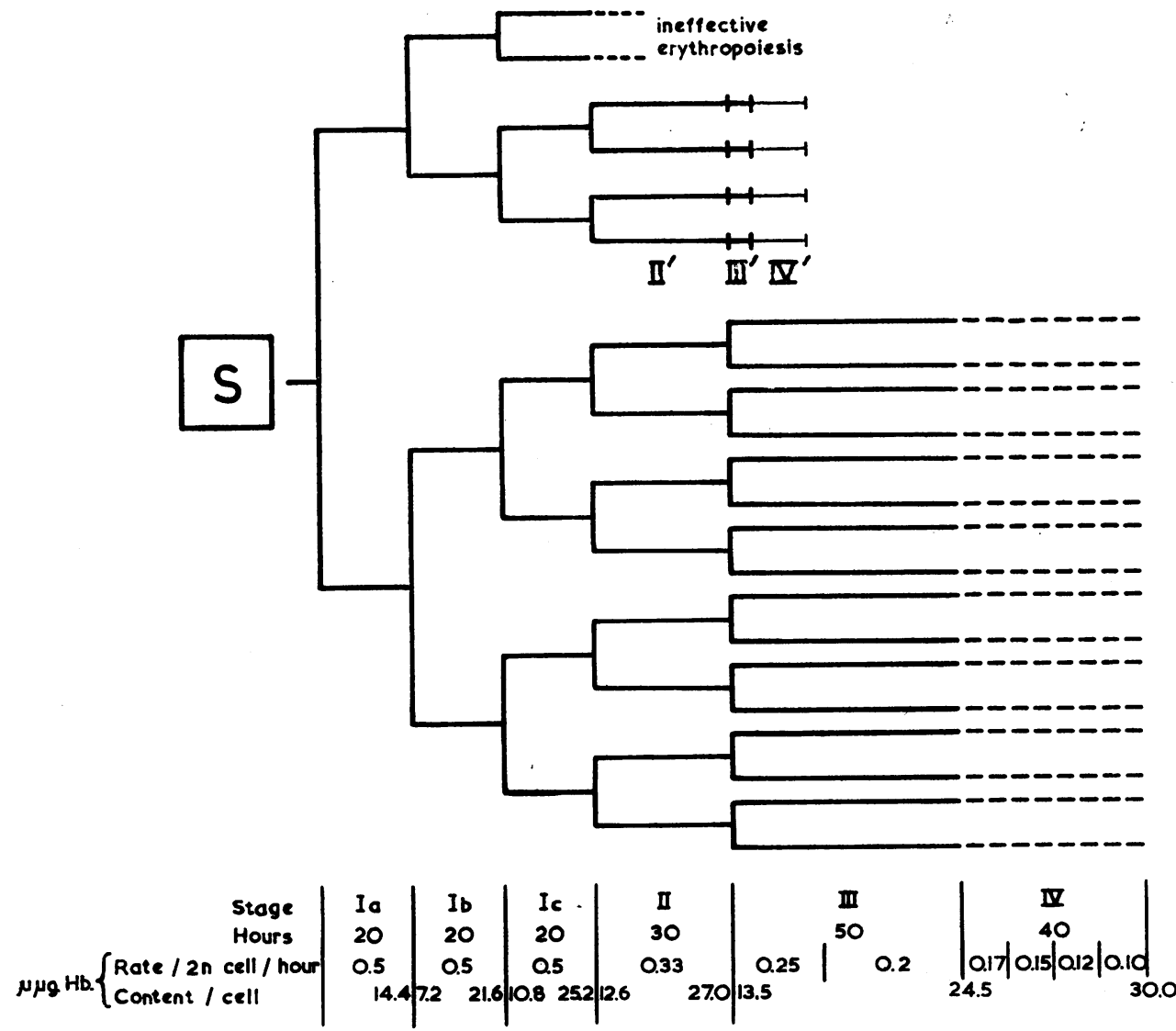

FIG. I.

marrow differential count, as is the life span of the marrow reticulocytes.

The model is illustrated in Fig. 1 .

It can be seen that there are three cell-cycles of 20 hours each in the early cell stages (pro- and basophilic (I)), followed by a 30-hour cell-cycle as early polychromatic normoblast (II), then a life span of about 50 hours (before loss of nucleus) as middle and late polychromatic normoblast(III), followed by a 40-hour stay as marrow reticulocyte (IV), after which the cell is released into the peripheral blood.

Some of the early polychromatic cells do not complete their division ( $\left(\mathrm{II}^{\prime}\right)$, and will be released after only a brief maturation (III' and IV').

\section{Independent Check of the Model}

The validity of every model depends on the number of available observations it can explain in respect of the system it purports to represent - and especially so if a number of these observations were not used in the construction of the model. Such independent observations may be used for checking the validity of the model.

(a) Mitotic Index of Erythroid Cells. From the model it can be seen that 21 mitoses occur in a population of 1,517 ' hours-worth' of cells (hoursworth $=$ sum of hours at each stage). Taking the duration of mitosis as one hour, the expected erythroid mitotic index would be $1.4 \%$. The measured mitotic index is, in fact, in good agreement, $1.6 \%$ (see discussion Lajtha and Oliver, I960).

(b) Total Erythroid Cellularity. According to the model one stem-cell/hour will produce 20 reticulocytes/hour with 1,517 normoblasts in between. The daily reticulocyte production in man, being $2 \times 10^{11}$ i.e. $8 \times 10^{9} /$ hour, requires $4 \times 10^{8}$ stem cells/hour. $4 \times 10^{8} \times 1,517=6 \times 10^{11}$ normoblasts in the normal human marrow. This agrees well with the figure found experimentally by Suit (1957).

(c) Hamoglobin Content of Cells. If the rate of ${ }^{59} \mathrm{Fe}$ uptake is equated with $0.5 \mu \mathrm{\mu g} /$ hour in the pro- 
normoblasts and basophilic normoblasts, then, using the relative rates described earlier, the mean hæmoglobin content of cells at different stages of maturation can be predicted. That of the blood reticulocyte will be $30 \mu \mu \mathrm{g}$ - in agreement with the known value, and in the basophilic normoblasts a mean value of $\mathrm{I}_{5} \mu \mathrm{g}$-in agreement with spectro-photometric data (Carvalho, 1959).

(d) ${ }^{59} \mathrm{Fe}$ Appearance in Blood. From the uptake rates indicated in the model, and from the maturation times illustrated in Fig. $I$, it can be calculated at what rate a tracer dose of ${ }^{59} \mathrm{Fe}$ would be expected to appear in the peripheral erythrocytes. The calculated curve is, for all purposes, identical with that found in man.

Further details of the model are discussed elsewhere (Lajtha and Oliver, I960), but it can be seen from the points mentioned above that most of the available direct information on nucleated red cells is in good agreement with, and can be predicted from the model. Hence it has a reasonable chance that it approximates the true behaviour of the erythron.

\section{The Stem-Cell Problem}

The model in Fig. I starts with the symbol $\mathrm{S}$ -this means the stem cell. The identity of the stem cell is still unknown, in spite of the great number of theories expounded on it in the literature. There is no a priori reason, however, why one should not know-to some extent at leasthow the stem cell works, even without knowing which cell it is. The first question to settle is, of course, the existence of a stem cell. By definition a stem cell is a cell which (a) can maintain its own numbers, and $(b)$ can give rise to differentiating cells. If, therefore, some of the early normoblasts (e.g. pronormoblasts) are a self-maintaining population, then they are the stem cell; if not, something else is the stem cell.

The question was elegantly solved by the experiments of Alpen and Cranmore (1959). They gave a tracer dose of ${ }^{59} \mathrm{Fe}$ to two groups of dogs, (a) control and $(b)$ severely bled. The latter were producing reticulocytes at a greatly increased rate. The two parameters which Alpen and Cranmore investigated on autoradiographs of serial bone-marrow samples following the radio-iron injections were: $(a)$ the grain-count halving-time, and $(b)$ the change with time of the proportion of labelled cells.

The grain-count halving-time $(t / 2)$ is the time required for the median grain-counts over, for example, pronormoblasts to reach $50 \%$ of the value shown at the beginning (e.g. two hours after ${ }^{59} \mathrm{Fe}$ injection). This time, or, in other words, the slope of decrease of median grain-counts in time, is due to the rate at which cells divide and thus halve their radio-iron content: i.e. it measureึ the cell cycle-time.

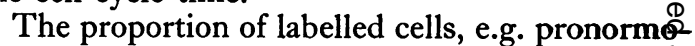
blasts after an injection of ${ }^{59} \mathrm{Fe}$ is practically $100 \%$ If these cells were a self-maintaining population, then, although the grain-counts over the cels would show an exponential fall with time, neves theless all cells would remain labelled. The aut radiographs, however, have shown that, even $\overrightarrow{\mathbf{i}^{\circ}}$ normal dogs, the proportion of labelled pronormo of blasts decreases with time, i.e. unlabelled pronof? moblasts are 'fed' into the labelled population $\vec{\theta}$ obviously from an unlabelled precursor (stem cell) population. The experiments further demorfs strated that stimulation of erythropoiesis (bleetit ing) does not change the intermitotic cycle-time of the normoblasts, i.e. grain-count $t / 2$, but it significantly increases the rate at which unlabelleg cells are fed into the poulation (decrease in pert centage labelled cells).

The important conclusions from these experib ments are twofold: $(a)$ the pronormoblasts are not a self-maintaining population of cells; they ar $\vec{e}$ produced by a precursor population which does not take up radio iron; and $(b)$ stimulation of erythropoiesis is effected by increasing the rate which cells of the precursor population (sterg cells) are transformed into pronormoblasts. 유

The kinetic picture of the bone marrow whole may then be considered as illustrated Fig. 2, where $\mathrm{S}$ is the stem cell 'compartments (population 1 ) with some kind of feedbac $\bar{B}$ mechanism, maintaining its own numbers; thi gives rise-by differentiation (? adaptive enzyme formation) - to the bone marrow cells 'proper constituting a differentiating and dividing com 3 partment (population 2), which finishes up as non-dividing differentiating compartment (population 3) before being released into the peripher

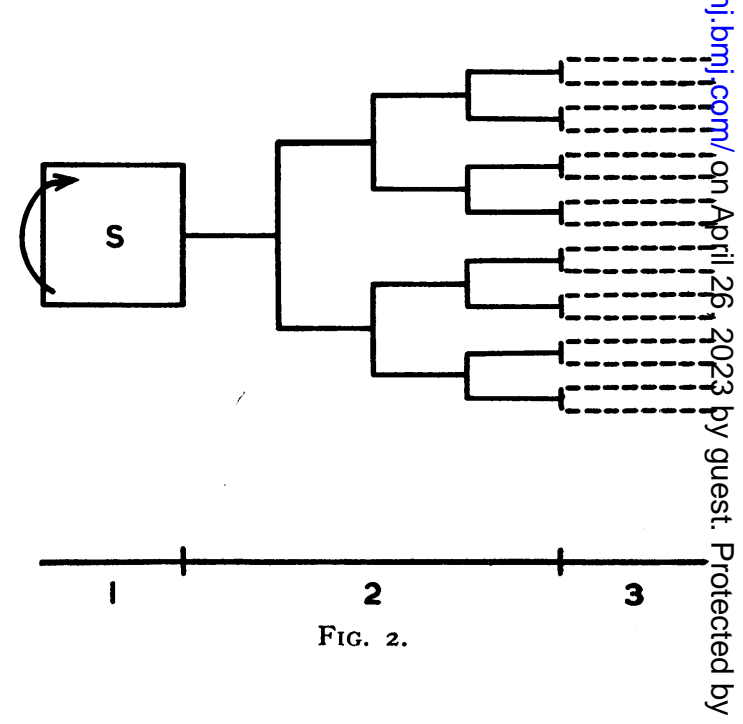


blood. The important aspect to realize is that differentiation is - for all intents and purposesan irreversible step, leading to a series of irrevocable changes, ending in a non-dividing cell with a limited life span. It is also obvious then, that while the maintenance of normal numbers of bone marrow cells 'proper' is essential, they are mere temporary 'guests in transit' in the marrow, the function of which-and the recovery of which after, for instance, a radiation damage -is maintained by the stem cell population (Lajtha, r96ra).

\section{Stem-Cell Kinetics}

The principal problem in stem-cell kinetics is hò any kind of 'stem' cells can maintain a steady state of cell production for differentiation and still maintain their own numbers. The classical concept was that of an asymmetric cell division: one stem cell divides and one of the daughter cells remains a stem cell, the other differentiates. This, of course, is an untenable concept as it does not allow stem-cell recovery from, e.g. radiation damage; for instance, the stem-cell population once depleted can only work faster but it can never return the stem population to normal levels. As animals can tolerate up to five to six doses of radiation, each producing a $90 \%$ depopulation-this would imply a 100,000-fold shortening of their cell cycle-which is clearly nonsense.

Recognizing this difficulty with the classical concept, Osgood (1957) introduced an alternative to the asymmetric $(\alpha-\alpha, n)$ division: the occasional symmetric $(\alpha-2 \alpha)$ division, resulting in two stem daughter-cells, as and when stem regeneration demands it. However, no explanation exists for the possible biochemistry of such a mechanism, nor can the existence of such a mechanism be proved experimentally.

The question may be raised: Is this the only way stem-cell steady-state can be explained? The answer is no! It is possible to construct a kinetic model of the bone-marrow cell populationbased on known and experimentally tested principles - several qualitative and quantitative aspects and predictions of which can be experimentally tested. The detailed quantitative kinetics will be published elsewhere (Lajtha, Oliver and Gurney, to be published). The essential features of the model, however, are as follows:

The stem cells are basically in a true resting state, that is, not in a state of cell cycle-like, for, example, the cells in resting liver. The population, however, has a feed-back mechanism, by which, if and when depopulation occurs, a suitable proportion of cells will be triggered off into a cell cycle terminating in cell division, as in liver regenerating after partial hepatectomy.

Although 'basically' in a state of no cell cycle, in reality the stem-cell population is never fully at rest, as a continuous removal mechanism (such as, for example, the humoral factor erythropoietin) operates, which removes a steady proportion of cells per unit time, and consequently the feed-back mechanism triggers off a steady proportion of cells into cell cycle. The 'removal' is envisaged as an induction of an enzyme-in case of erythropoietin perhaps a hæmoglobin-synthesizing enzyme - the cells being induced, by definition, not being stem cells any more, but differentiating cells.

In a normal steady state, therefore, a certain proportion of cells will be induced (are differentiating) per unit time, a similar number will be triggered off per unit time, and a similar number of divisions will occur per unit time. At any given time, therefore, a proportion of the stem cells will be in a state of cell cycle (triggered stock) and a further proportion in a true resting state (available stock). The available stock is so called because the cells are available for differentiation (? enzyme induction) or triggering, but the triggered cells are not available for differentiation (nor for further triggering) until they have completed their cell cycle and mitosis, after which both daughter cells become 'available stock'.

The statement that triggered cells are not available for differentiation is easily checked: if they were, the stem cell population (and, consequently, the bone marrow) would be expected to run down on extreme stimulation, especially if this is started shortly after irradiation injury. The experimental findings, however, indicate that $(a)$ no experimental stimulation can run down the bone marrow and $(b)$ post-irradiation stimulation, in fact, is beneficial: it enhances recovery. This latter observation is predictable only if the concept of 'triggered cells not available for differentiation' is accepted.

The principles outlined above can be further tested by assigning arbitrary numerical values to its parameters and by serial calculations of the expected sequence of events. Such calculations have been performed in our laboratory during the last year and several unexpected features of the scheme have already been tested experimentally and were confirmed. The best available test system for the functional integrity of bone-marrow stem cell is the response of a hypertransfused mouse to a standard test dose of erythropoietin (Filmanowitz and Gurney, 196r).

It may be worth mentioning that the experimental data at present available seem to indicate that the bone-marrow stem is pluripotential. 
Whether this pluripotentiality is for erythro- and myelopoiesis, or erythro- and thrombopoiesis, or for all three lines of cells, remains to be found out by further experiments.

\section{Some Practical Considerations}

There are certain practical aspects of the kinetics of the bone marrow which may be worth consideration.

The first aspect concerns the mechanism of action of erythropoietin. At present there is a considerable amount of discussion in the literature as to the number and mode of action of various factors stimulating erythropoiesis. The first question is, of course, how erythropoiesis is measured. The two commonest methods are the reticulocyte count and the ${ }^{59} \mathrm{Fe}$ incorporated (this, in this respect, means the proportion of a tracer dose of ${ }^{59} \mathrm{Fe}$ which appears in the peripheral erythrocytes at some standard time after administration). Other methods measure total red-cell volume; others again mitotic index in the bone marrow; some estimate the ${ }^{59} \mathrm{Fe}$ taken up by the bone marrow at some short time after administration of the tracer.

What do these parameters, in fact, measure?

Reticulocyte numbers in the peripheral blood are influenced by at least three factors: $(a)$ the number of stem cells differentiating into the erythron per unit time, $(b)$ the ratio of the two pathways (II and $\left.\mathrm{II}^{\prime}\right)$ in Fig. I and $(c)$ the life span of the reticulocyte (maturation time) in the blood. Increasing the rate of stem-cell differentiation, increasing the proportion of the II as referred to the II' pathway, increasing the life span of the blood reticulocyte (decreasing rate of maturation or earlier release from the marrow)-all these three factors, single or combined, will result in elevated reticulocyte counts at some time.

The case is similar with the appearance of ${ }^{59} \mathrm{Fe}$ in the blood or its uptake into the marrow: increased stem-cell differentiation will increase the total nucleated red cells in the marrow, hence a greater proportion of the ${ }^{59} \mathrm{Fe}$ will be taken up by red-cell precursors (as opposed to iron stores). However, increasing the importance of the II as opposed to the II' pathway will also increase the number of (late) normoblasts which then are available for ${ }^{59} \mathrm{Fe}$ uptake. It is, perhaps, unnecessary to emphasize that changes in the plasma iron-pool will significantly effect ${ }^{59} \mathrm{Fe}$ incorporation, an aspect of ${ }^{59} \mathrm{Fe}$ studies which, nevertheless, is forgotten with regrettable frequency.

The mitotic index of the marrow could increase simply by elongating the duration of the mitotic process; it would be expected to increase by any mechanism increasing the proportion of nucleated red cells over the white-cell precursors (the latter population, as a whole, has a lower mitotic ind than the erythroid population); and it would expected to increase even in the erythroid popul 8 tion at some time after stimulating the differentiation of stem cells into the erythron (in which case $a$ wave of early normoblasts-which have the highest intrinsic mitotic index as a population-w sweep through the erythron). Changes in the erythroid mitotic index due to a shift in the

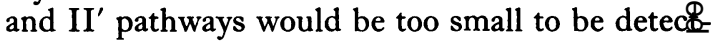
table with any accuracy.

Polycythæmia may result from increased stern cell differentiation into the erythron, but it must be remembered that abolishing the II' pathway would also increase the red-cell production about $20 \%$.

It may be concluded, therefore, that any agent, the effect of which is measured in normal anim by the above parameters, could produce that effect by a number of entirely different and unrelated mechanisms. This, of course, would make the definition of any 'erythropoietin' very vagqe indeed.*

There is one aspect of erythropoiesis, howevef, which can be measured clearly and unequivocal and that is the rate of differentiation of stem cells into the erythron-and the only method which measures this parameter safely is the respong a standard test dose in the polycythamic mouse. That animal has the advantage that prior to ministration of the test material (and for seve days if no effective material is given) it has measurable endogenous erythropoiesis. The parmeter which, in fact, is measured in such an aningal is the induction of erythropoiesis where there none. It is strongly suggested, therefore, that the term 'erythropoietin activity' should be reserved for such preparations of materials orfy which can elicit a wave of erythropoiesis in the polycythæmic mouse. Any material which stimilates red-cell production or ${ }^{59} \mathrm{Fe}$ uptake in normen, but not in polycythæmic, animals should not called 'erythropoietin' (or vice versa).

Other aspects of bone-marrow kinetic studes concern the combating of radiation damage qo the bone marrow. The amount of experimental information available, however, is not sufficient enable conclusive statements to be made. The model of stem-cell kinetics would predict a bereficial effect of even post-irradiation stimulation ${ }^{\prime} f$ stem-cell differentiation, either by erythropoiets administration shortly after irradiation or by myetopoietic stimulation at any time after irradiation. Experiments to test both the quantitative a d qualitative predictions are in progress and the

* It is not intended to complicate matters unduly, but materials causing an increase in red-cell count, but got in hæmatocrit values, have also been reported. 
is some evidence-qualitative at least-which supports these predictions. Leukocytosis-promoting agents indeed enhance bone-marrow regeneration after irradiation (Smith, Alderman and Gillespie, 1958). The availability for testing of a physiological leukocytosis-inducing factor (Gordon, Neri, Siegel, Dornfest, Handler, Lobue and Eisler, 1960) would be of great value in this respect.
Due to their short life-span in the circulation and to the lack of suitable specific label, the quantitative kinetics of myelopoiesis and thrombopoiesis are not sufficiently understood. It is hoped that future work will provide some much needed information on these problems, as well as extending our knowledge of bone-marrow stem-cell kinetics - perhaps even to the extent of eventually recognizing which cell the stem cell is.

\section{REFERENCES}

Alpen, E. L., and Cranmore, D. (1959): Observations on the Regulation of Erythropoiesis and on Cellular Dynamics by $\mathrm{Fe}^{59}$ Autoradiography, 'Kinetics of Cellular Proliferation', p. 290, ed. F. Stohlman. New York: Grune and Stratton.

CarvalHo, S. (1954): Estudios sobre a hemoglobinogenese no eritroblasto, Edicso de Gazeta Medica Portugesa.

Filmanowitz, E., and GURNEY, C. W. (1961): Studies on Erythropoiesis: XVI-The Response to a Single Dose of Erythropoietin in the Polycythæmic Mouse, f. Lab. clin. Med., 57, 65.

Gordon, A. S., Neri, R. O., Siegel, C. D., Dornfest, B. S., Handler, E. S., Lobue, J., and Eisler, M. (1960): Evidence for a Circulating Leukocytosis-inducing Factor, Acta Hamatol., 23, 323.

Lajtha, L. G. (1957): Bone Marrow Cell Metabolism, Physiol. Rev., 37, 50.

, Oliver, R., BerRy, R. J., and Hell, E. (1960): Analysis of Metabolic Rates at the Cellular Level, Nature (Lond.), I87, 919 .

(1960): Studies in the Kinetics of Erythropoiesis: A Model of the Erythron, Ciba Foundation Symposium, 'Hæmopoiesis ', p. 289 (also discussion on p. 314). London: Churchill.

(r96ra): The Effect of Ionizing Radiations and Tumour Chemotherapeutic Agents on the Bone Marrow, Progress in Biophysics, 11, 79.

(196Ib): Autoradiography in Bone Marrow Studies, 'The Scientific Basis of Medicine Annual Reviews', p. 63. London University: Athlone Press.

, Oliver, R., and Gurney, C. W.: Kinetic Model of a Bone Marrow Stem Cell Population. To be published.

Osgood, E. E. (1957): A Unifying Concept of the Ætiology of Leukæmias Lymphomas and Cancers, F. Nat. Ca. Inst., 18, 155 .

Smith, W. W., Alderman, I. M., and Gillespie, R. E. (1958): Hæmatopoietic Recovery Induced by Bacterial Endotoxin in Irradiated Mice, $\mathcal{F}$. Physiol. (Lond.), 192, 549.

Surt, H. D. (1957): A Technique for Estimating the Bone Marrow Cellularity in vivo using ${ }^{59} \mathrm{Fe}$, f. clin. Path., $10,267$. 